\title{
Determination of Alkyl Esters Content in PDO Extra Virgin Olive Oils from Sicily
}

\author{
Rosaria Costa, ${ }^{1}$ Giovanni Bartolomeo, ${ }^{1}$ Emanuele Saija, \\ Rossana Rando, ${ }^{1}$ Ambrogina Albergamo, ${ }^{1}$ and Giacomo Dugo ${ }^{1,2}$ \\ ${ }^{1}$ Dipartimento di Scienze Biomediche, Odontoiatriche, e delle Immagini Morfologiche e Funzionali (BIOMORF), \\ University of Messina, Messina, Italy \\ ${ }^{2}$ Science4Life S.r.l., A Spin-Off of the University of Messina, Messina, Italy \\ Correspondence should be addressed to Rosaria Costa; costar@unime.it
}

Received 28 July 2016; Revised 27 September 2016; Accepted 16 October 2016; Published 10 January 2017

Academic Editor: José A. Beltrán

Copyright (C) 2017 Rosaria Costa et al. This is an open access article distributed under the Creative Commons Attribution License, which permits unrestricted use, distribution, and reproduction in any medium, provided the original work is properly cited.

\begin{abstract}
The quality parameter of alkyl esters of fatty acids was checked in a variety of Italian olive oil samples. In particular, 34 samples of extra virgin olive oils (EVOOs) from South Italy (Sicilian orchards), produced in the years 2014-2015, have been subjected to the analytical protocol dictated by the European Union for the determination of alkyl esters, as an indicator of oil's quality. All the samples analyzed resulted to be well below the limit set by EU Directive. Besides recently produced EVOOs, a set of very aged oils, produced in the years 1996-2000, were analyzed as well. The main finding was that alkyl esters increased in correspondence with deterioration processes.
\end{abstract}

\section{Introduction}

With no doubt, olive oil represents a food commodity of inestimable value, from both the nutritional and the economic point of view. International legislation recognizes officially different categories of olive oils, mainly based on the value of free acidity (expressed as oleic acid), sterols and waxes content, fatty acid composition, organoleptic evaluation, peroxide number, ethyl esters of fatty acids, and UV spectroscopy assays [1]. Therefore, besides the most valuable extra virgin olive oil, other types of olive oil are available in the market: virgin, lampante, refined, refined mixed with virgin oils, pomace (crude and refined), and ordinary (not present in EU Regulation). Worldwide consumption of olive oil has increased by a $2.2 \%$ factor in almost twenty years [2]. This finding can be safely attributed to the well-recognized beneficial effects of olive oil, which is the basic food product of the "Mediterranean diet." In 2010, the latter has been indeed declared as part of "UNESCO intangible cultural heritage." Furthermore, there is an increasing trend from nutritionists to propose the Mediterranean diet as a lifestyle opposed to the deleterious eating habits of modern life. In contrast to food rich of saturated fats and proteins, olive oil offers a variety of unsaturated fatty acids and polyphenols. Among those countries where the consumption of olive oil has always been scarce, USA have started in the last years to increase the demand of olive oil, accounting for about $9 \%$ of global consumption [3]. In consideration of this, olive oil is today regarded as a valuable commodity, making it a common target of illicit manipulations and frauds. As a matter of fact, olive oil production and marketing in Europe is subjected to a series of regulations, which set specific parameters in order to guarantee olive oil's genuineness and consequently consumer's safety. Starting from Commission Regulation (EEC) number 2568/91 [4] and passing through successive modification (EC) number 1996/92 [5, 6], all the operators of olive oil's sector must comply with specific requirements, in terms of both production and quality control of the final product prior to introduction in the market. Basically, a set of chemicophysical analyses carried out on the final product allow assessing its integrity and understanding if any irregular raw material or illicit procedures have been adopted. However, as far as technology moves on, food adulteration becomes sharper and tough to be unveiled. Commission 
Regulation (EU) number 61/2011 [7] and successive modification (EU) number 1348/2013 introduce alkyl esters of fatty acids, and specifically the ethyl esters, in the decision tree for the quality criteria, because this marker is able to detect fraudulent mixtures of extra virgin olive oils with lower quality oils. The latter could belong to the categories of virgin, lampante, or deodorized oils, even though alkyl esters are considered specific markers of the prime material (olives). An increment of alkyl esters can be observed in EVOOs obtained from olives of not good quality, that is, damaged or stored under bad conditions. In such cases, production of ethanol from fermentation of olive sugars, and of free fatty acids from lipolysis, is a common occurrence which triggers alkyl esters synthesis. Nonetheless, it seems worthwhile to mention briefly the illegal procedure of adding deodorized oils to extra virgin olive oils. Deodorization is actually a stripping process to remove off-flavours in edible oil processing. For instance, "lampante" olive oil, which is not edible because of its free fatty acids and off-flavours' contents, is subjected to this procedure to be commercialized. Generally, in deodorization, steam is passed through hot oil under reduced pressure at temperatures higher than $200^{\circ} \mathrm{C}$. After treatment, the oil is mixed with olive oil or EVOO and marketed as "olive oil," which is of course less valuable than EVOO. Normally, deodorization highly affects some specific chemicophysical parameters, making deodorized oils easily distinguishable from EVOOs. Recently, a mild version of deodorization is becoming popular in olive oil's adulteration, which makes oils able to pass traditional tests applied for quality check. Mild deodorization takes place at lower temperatures $\left(120^{\circ} \mathrm{C}\right)$, for a reduced time and under vacuum. It is estimated that this type of adulteration is dramatically diffused, especially in consideration of the alarmingly low cost of numerous brands of EVOOs that can be found in the shelves of supermarkets. As established by Regulation EU number 61/2011, the presence of mildly deodorized oils in EVOOs is accompanied by a parallel increment of methyl and ethyl esters of fatty acids (FAMEs and FAEEs) in treated oils. Such compounds normally derive from esterification of free fatty acids with short-chain alcohols (ethanol and methanol). Their level in olive oil depends upon availability of precursors and enzymes, as such in the case of using over-ripened olives for oil production.

In the present study, numerous samples of EVOO from Sicilian varieties of olives and orchards were investigated about their content of alkyl esters. When possible, aged EVOOs were analyzed as well, and their amount of alkyl esters compared with that of recently produced samples. Previously, the content of fatty acids and selenium in relation to zone of provenance and variety was explored [8-11].

\section{Materials and Methods}

2.1. Samples and Chemicals. Samples under investigation were 34 extra virgin olive oils (EVOOs), mostly produced in the year 2015 from 11 varieties of olives harvested in 17 different sites in Sicily, Italy, and six aged EVOOs, produced from Sicilian olives in the years 1996-2000. A list of samples with their description has been reported in Table 1. All samples were kindly provided by local producers of olive oil. $70 \%$ of samples had "protected designation of origin" (PDO).

Silica gel 60 M 0.04-0.063 mm/230-400 mesh ASTM for column chromatography was supplied by Macherey-Nagel (Duren, Germany); heptane (99.7\% purity) was purchased from VWR Prolabo (Fontenay-sous-Bois, France); hexane, ethyl alcohol, chloroform, acetic acid, and methyl heptadecanoate $(\geq 99.0 \%)$ were provided by Sigma Aldrich (St. Louis, MO, USA); ethyl ether was from Merck KGaA (Darmstadt, Germany); phenolphthalein, potassium iodide, and starch were from Carlo Erba reagents (Milan, Italy); sodium thiosulfate and potassium hydroxide were supplied by Titol Chimica (Rovigo, Italy).

2.2. Isolation of Alkyl Esters. For the extraction of fatty acid methyl and ethyl esters (FAMEs and FAEEs), the official procedure reported in the Regulation EU number 61/2011 was applied to the whole set of samples. The preliminary phase of extraction consisted of the preparation of the chromatographic column. For this purpose, $15 \mathrm{~g}$ of silica gel was suspended in n-hexane and packed in a column. The solvent was allowed to drain to prevent overflowing. Afterward, the stationary phase was left to settle by gently tapping the column, at first instance, successively with the aid of electric vibration, so as to pack tightly the stationary phase into the column. About $30 \mathrm{~mL}$ of $\mathrm{n}$-hexane was percolated through the column for removing interferences. An aliquot of $500 \mathrm{mg}$ of EVOO was weighed and added with $0.225 \mathrm{~mL}$ of a $0.02 \% \mathrm{w} / \mathrm{v}$ of a methyl heptadecanoate solution in $\mathrm{n}$ heptane, used as internal standard. The obtained solution was transferred into the chromatographic column, in two steps (two aliquots of $2 \mathrm{~mL}$-hexane). For elution of analytes, a mixture of $n$-hexane/ethyl ether $(99: 1)$ was used, at a rate of about 15 drops $/ 10 \mathrm{sec}$. The volume of the collected fraction, containing alkyl esters, was $220 \mathrm{~mL}$. This fraction was transferred into a rotary evaporator (Buchi, Cornaredo, Italy) to remove solvents, until reaching a $2 \mathrm{~mL}$ volume. At this point, a nitrogen stream was applied for complete solvent's removal. The residue was redissolved in $2 \mathrm{~mL}$ of $\mathrm{n}-$ heptane for successive GC analysis.

2.3. Determination of Free Acidity and Peroxide Value. For the determination of free acidity, the following procedure was carried out. $90 \mathrm{~mL}$ of a solution of ethyl alcohol/diethyl ether $(1: 2)$ was added with some drops of $1 \%$ phenolphthalein (indicator) and successively neutralized with $0.1 \mathrm{~N}$ potassium hydroxide (titrant). The mixture was then added with $5 \mathrm{~g}$ of olive oil and titrated with $0.1 \mathrm{~N}$ potassium hydroxide until colour change was observed. The acidity value was calculated from this equation and expressed as \% of oleic acid:

$$
\operatorname{acidity}(\%)=\frac{V \times N \times M_{\mathrm{OA}}}{M_{S} \times 10} \text {, }
$$

where $V$ is the volume $(\mathrm{mL})$ of titrant $(\mathrm{KOH}), N$ is normality of titrant $(0.1), M_{\mathrm{OA}}$ is the molecular weight of oleic acid (282), and $M_{S}$ is the oil sample weight (g). 
TABLE 1: List of extra virgin olive oil (EVOO) samples with indication of olive variety and place of origin, year of production, and "protected designation of origin" (PDO) qualification.

\begin{tabular}{|c|c|c|c|c|}
\hline Sample number & Olive variety & Production year & Area of production & $\mathrm{PDO}$ \\
\hline 1 & Nocellara etnea & 2015 & Linguaglossa (CT) & $\checkmark$ \\
\hline 2 & Nocellara etnea & 2015 & Linguaglossa (CT) & $\checkmark$ \\
\hline 3 & Nocellara messinese & 2015 & Ficarra (ME) & \\
\hline 4 & Minuta & 2015 & Ficarra (ME) & $\checkmark$ \\
\hline 5 & Coratina & 2015 & Ficarra (ME) & \\
\hline 6 & Nocellara messinese & 2015 & Ficarra (ME) & \\
\hline 7 & Sambenedettese & 2015 & Furnari (ME) & \\
\hline 8 & Biancolilla/Nocellara del Belice & 2015 & Mazzara (TP) & $\checkmark$ \\
\hline 9 & Nocellara del Belice & 2015 & Caronia (ME) & $\checkmark$ \\
\hline 10 & Nocellara del Belice & 2015 & Menfi (AG) & $\checkmark$ \\
\hline 11 & Minuta & 2015 & S. Domenica Vittoria (ME) & $\checkmark$ \\
\hline 12 & Nocellara del Belice & 2015 & Alcamo (TP) & $\checkmark$ \\
\hline 13 & Nocellara del Belice & 2015 & Alcamo (TP) & $\checkmark$ \\
\hline 14 & Verdella & 2014 & Patti (ME) & \\
\hline 15 & Verdella & 2015 & Patti (ME) & \\
\hline 16 & Nocellara messinese & 2015 & Patti (ME) & \\
\hline 17 & Ogliarola/Biancolilla/Nocellara/Verdella & 2015 & Patti (ME) & $\checkmark$ \\
\hline 18 & Uovo di Piccione & 2015 & Furnari (ME) & \\
\hline 19 & Minuta & 2014 & Ficarra (ME) & $\checkmark$ \\
\hline 20 & Minuta & 2015 & Ficarra (ME) & $\checkmark$ \\
\hline 21 & Santagatese/Biancolilla & 2015 & S. Salvatore Fitalia (ME) & $\checkmark$ \\
\hline 22 & Ogliarola messinese/Biancolilla & 2015 & Furnari (ME) & $\checkmark$ \\
\hline 23 & Ogliarola messinese/Biancolilla & 2015 & Furnari (ME) & $\checkmark$ \\
\hline 24 & Nocellara del Belice, Biancolilla, Ogliarola & 2015 & Marsala (TP) & $\checkmark$ \\
\hline 25 & Minuta & 2015 & Tortorici (ME) & $\checkmark$ \\
\hline 26 & Verdella & 2015 & Furnari (ME) & \\
\hline 27 & Nerba, crastu & 2015 & Pollina (PA) & \\
\hline 28 & Nerba, crastu & 2015 & Pollina (PA) & \\
\hline 29 & Nerba, crastu & 2015 & Pollina (PA) & \\
\hline 30 & Biancolilla & 2015 & Librizzi (ME) & $\checkmark$ \\
\hline 31 & Nocellara del Belice & 2015 & Corleone (PA) & $\checkmark$ \\
\hline 32 & Nocellara del Belice & 2015 & Campobello (TP) & $\checkmark$ \\
\hline 33 & Nocellara del Belice & 2015 & Campobello (TP) & $\checkmark$ \\
\hline 34 & Nocellara del Belice & 2015 & Campobello (TP) & $\checkmark$ \\
\hline 35 & Ogliarola messinese & 1998 & Brolo (ME) & $\checkmark$ \\
\hline 36 & Ogliarola messinese & 2000 & Brolo (ME) & $\checkmark$ \\
\hline 37 & Cerasuola & 1996 & Sciacca $(A G)$ & $\checkmark$ \\
\hline 38 & Cerasuola & 1998 & Monreale (PA) & $\checkmark$ \\
\hline 39 & Biancolilla & 1998 & Sciacca (AG) & $\checkmark$ \\
\hline 40 & Biancolilla & 1997 & Brolo (ME) & $\checkmark$ \\
\hline
\end{tabular}

For the determination of peroxide value, the NGD C 35-1976 method was used. $25 \mathrm{~mL}$ of a glacial acetic acid/chloroform $(3: 2)$ solution was added with $500 \mu \mathrm{L}$ of a supersaturated solution of potassium iodide. After vigorously shaking for about $1 \mathrm{~min}$, the solution was allowed to stand in the dark for about $5 \mathrm{~min}$. Successively, after addition with $75 \mathrm{~mL}$ distilled water and starch indicator, a titration with $0.01 \mathrm{~N}$ sodium thiosulfate was carried out until colour change was observed. The peroxide value, defined as the amount of peroxide oxygen per $1 \mathrm{~kg}$ of oil, was calculated from the following equation and expressed as units of milliequivalents:

$$
\text { peroxide value }=\frac{V \times N \times 1000}{M_{S}},
$$

where $V$ is the volume $(\mathrm{mL})$ of titrant $\left(\mathrm{Na}_{2} \mathrm{~S}_{2} \mathrm{O}_{3}\right), N$ is normality of titrant $(0.01)$, and $M_{S}$ is the oil sample weight (g). 
2.4. GC Analysis. GC-FID analyses were performed on a GC2010 system (Shimadzu, Japan), equipped with a Zebron-5 ms column (Phenomenex, Torrance, USA), $12 \mathrm{~m} \times 0.20 \mathrm{~mm}$ I.D. $\times 0.33 \mu \mathrm{m} d_{f}$. Oven temperature program was from $80^{\circ} \mathrm{C}$ to $140^{\circ} \mathrm{C}$ at $20^{\circ} \mathrm{C} / \mathrm{min}$ and to $335^{\circ} \mathrm{C}$ at $5^{\circ} \mathrm{C} / \mathrm{min}$ and held for $20 \mathrm{~min}$. Injection took place in direct mode. Injector and FID temperatures were $320^{\circ} \mathrm{C}$ and $350^{\circ} \mathrm{C}$. Carrier gas was $\mathrm{He}$, at a linear velocity of $57.5 \mathrm{~cm} / \mathrm{s}(186 \mathrm{kPa})$. Detector gases were hydrogen $(40 \mathrm{~mL} / \mathrm{min})$, nitrogen $(40 \mathrm{~mL} / \mathrm{min})$, and air $(400 \mathrm{~mL} / \mathrm{min})$. Data were processed by GCsolution software (Shimadzu). For GC/MS analyses, a GCMS-QP2010 system (Shimadzu, Japan) was used, equipped with a Zebron-5 ms column (Phenomenex, Torrance, USA), $30 \mathrm{~m} \times 0.25 \mathrm{~mm}$ I.D. $\times 0.25 \mu \mathrm{m} d_{f}$. Oven temperatures were $250^{\circ} \mathrm{C}$ and $200^{\circ} \mathrm{C}$; EI was $0.94 \mathrm{kV}$; mass range was $40-500 \mathrm{~m} / z$; scan speed was $1,000 \mathrm{amu} / \mathrm{s}$. Data handling was by GCMSsolution (Shimadzu). The system was equipped with commercial (Wiley, NIST11) mass spectral databases.

\section{Results}

Table 1 reports a list of 40 samples of Italian (Sicilian) EVOOs analyzed in this study. Samples from number 1 to number 34 were produced in the season 2015, with only two EVOOs produced in the previous season (2014). Samples from number 35 to number 40 were aged EVOOs, produced in the years 1996-2000. All EVOOs were produced in Sicily, which is a South-Italian region/island, surrounded by the Mediterranean Sea. More specifically, EVOO samples came from the countryside of five main towns, namely, Catania (CT), Messina (ME), Palermo (PA), Trapani (TP), and Agrigento (AG). Within the same town's neighbourhood, localities of orchards were specified. On the other hand, samples were also classified on the basis of olive's variety used for a specific oil's production. Numerous were the oils falling into the "protected designation of origin" (PDO) category. All samples were analyzed for their content of alkyl esters (methyl and ethyl esters of palmitic and oleic acids), in compliance with the procedure reported by Regulation (EU) number 61/2011. Relative results have been presented in Table 2, where quantitative data of fatty acid methyl esters (FAMEs), fatty acid ethyl esters (FAEEs), whole fraction of alkyl esters (FAAEs), and FAEEs/FAMEs ratios, free acidity and peroxide value, have been reported.

According to the Regulation, the contents of FAAEs were reported as $\mathrm{mg} / \mathrm{kg}$ and calculated through the application of the following equation:

$$
\operatorname{FAEE}(\mathrm{mg} / \mathrm{kg})=\frac{A_{x} \cdot m_{s} \cdot 1000}{A_{s} \cdot m},
$$

where $A_{x}$ is the GC peak area of the alkyl ester to be quantified, $m_{s}$ is the amount of internal standard (mg), $A_{s}$ is the GC peak area of the internal standard, and $m$ is the amount of sample $(\mathrm{g})$. Each value reported in table is average of three repetitive GC injections; standard deviations were on average in the following range: $0.05-1.0$.

The lowest content of FAAEs ( $\sum$ FAEEs + FAMEs) was observed in sample number $18(1.6 \mathrm{mg} / \mathrm{kg})$ and the highest in sample number $35(144.5 \mathrm{mg} / \mathrm{kg})$. Fresh EVOOs reported values of FAAEs in the range $1.6-58.9 \mathrm{mg} / \mathrm{kg}$. This range was considerably different for old EVOOs, being 110.6$144.5 \mathrm{mg} / \mathrm{kg}$. When taking into account the contents of single groups of esters, ranges of $1.0-35.0 \mathrm{mg} / \mathrm{kg}$ and $70.0-$ $86.0 \mathrm{mg} / \mathrm{kg}$, for FAEEs in fresh and aged EVOOs, respectively, could be assessed. Among fresh EVOOs, sample number 25 reported the maximum value of FAEEs allowed by Regulation, evidencing a fermentative process attributable to not optimal storage conditions.

Free acidity values were in the range $0.1-0.7 \%$ with an average value of $0.4 \%$ for young EVOOs, whereas much higher values were obtained from aged EVOOs (5.6-8.5\%). Peroxide values ranged from 4.5 to $18.0 \mathrm{mEq} / \mathrm{kg}$, with a mean value of $7.6 \mathrm{mEq} / \mathrm{kg}$ in fresh EVOOs; even in this case, values dramatically increased for aged oils: $45.0-70.0 \mathrm{mEq} / \mathrm{kg}$.

Alkyl esters were analyzed by means of both GC-FID and GC-MS systems. The mass spectrometric detector supported identification of analytes. A GC-MS profile of FAMEs and FAEEs relative to sample number 39 (an aged EVOO) is shown in Figure 1.

Figure 2 shows a barplot reporting the whole set of EVOOs (fresh and aged), grouped by the locality of origin. The different groups of samples are reported based on the content of ethyl esters $(\mathrm{mg} / \mathrm{kg})$ and grouped by colour. Two borderlines designate the limit set by Directive (EU) number $1830 / 2015$ [12] and the average content experimentally determined, respectively.

\section{Discussion}

The Italian production of olive oil consists of about 600,000 tons/year, which corresponds to a $20 \%$ fraction of the global production. Double is instead the production of olive oil by Spain, representing about $40 \%$ of the total. Nonetheless, it must be emphasized that the Italian production is characterized by a high quality standard, testified by the highest number of "protected designation of origin" (PDO) products, which is 41 versus 25 of Spain. Besides PDOs, Italy produces also a "Protected Geographical Indication" (PGI) oil. PDO and PGI are EU classifications to define, in the first case, an agricultural or food product whose entire production cycle occurs in a specific geographical area (cannot be reproduced elsewhere); in the second case, when a single stage of the production cycle is connected with a specific geographical area, although in Italy PGI and PDO are quite similar. As can be seen in Table 1, 28 EVOOs analyzed in this study were PDOs. The application of the analytical protocol reported in the Directive EU 61/2011 led to the conclusion that all fresh EVOOs had an ethyl esters content $\leq 35 \mathrm{mg} / \mathrm{kg}$, which is the limit set by the present Regulation EU 1830/2015.

In this sense, the present report demonstrated that an increment of FAEEs can be observed also in aged EVOOs, where deterioration processes (i.e., oxidation and lipolysis) took place. This is not surprising, if considering the triglycerides breakdown occurring during EVOO's aging, which makes available free fatty acids (substrates for alkyl esters synthesis). In general, studies about alkyl esters in 
TABLE 2: Content of fatty acid alkyl esters (FAAEs), peroxide value, and free acidity in extra virgin olive oils. FAEEs: fatty acid ethyl esters; FAMEs: fatty acid methyl esters.

\begin{tabular}{|c|c|c|c|c|c|c|}
\hline Sample number & FAEEs $(\mathrm{mg} / \mathrm{kg})$ & FAMEs (mg/kg) & FAAEs $(\mathrm{mg} / \mathrm{kg})$ & FAEEs/FAMEs & Acidity (\%) & Peroxides $\left(\mathrm{mEq} / \mathrm{O}_{2} / \mathrm{kg}\right)$ \\
\hline 1 & 2.0 & 1.4 & 3.4 & 1.4 & 0.3 & 6.8 \\
\hline 2 & 6.3 & 5.9 & 12.2 & 1.1 & 0.4 & 5.6 \\
\hline 3 & 2.4 & 1.4 & 3.8 & 1.7 & 0.5 & 10.5 \\
\hline 4 & 2.6 & 1.5 & 4.1 & 1.7 & 0.3 & 6.1 \\
\hline 5 & 1.2 & 0.9 & 2.1 & 1.4 & 0.1 & 7.2 \\
\hline 6 & 1.8 & 1.8 & 3.6 & 1.0 & 0.2 & 11.2 \\
\hline 7 & 7.5 & 16.4 & 23.9 & 0.5 & 0.4 & 6.1 \\
\hline 8 & 1.5 & 1.2 & 2.7 & 1.3 & 0.3 & 5.2 \\
\hline 9 & 14.5 & 10.8 & 25.3 & 1.3 & 0.3 & 4.5 \\
\hline 10 & 3.1 & 2.3 & 5.4 & 1.4 & 0.3 & 5.3 \\
\hline 11 & 3.9 & 4.7 & 8.6 & 0.8 & 0.5 & 7.8 \\
\hline 12 & 4.7 & 4.2 & 8.9 & 1.1 & 0.3 & 8.4 \\
\hline 13 & 1.6 & 1.4 & 3.0 & 1.2 & 0.3 & 9.2 \\
\hline 14 & 2.2 & 2.4 & 4.6 & 0.9 & 0.6 & 18.0 \\
\hline 15 & 1.5 & 1.1 & 2.6 & 1.4 & 0.6 & 12.3 \\
\hline 16 & 2.2 & 3.2 & 5.4 & 0.7 & 0.5 & 6.4 \\
\hline 17 & 1.2 & 0.7 & 1.9 & 1.8 & 0.4 & 7.2 \\
\hline 18 & 1.0 & 0.6 & 1.6 & 1.7 & 0.3 & 5.1 \\
\hline 19 & 1.7 & 1.4 & 3.1 & 1.2 & 0.4 & 8.3 \\
\hline 20 & 2.6 & 2.8 & 5.4 & 0.9 & 0.4 & 7.6 \\
\hline 21 & 4.5 & 4.7 & 9.2 & 0.9 & 0.5 & 10.5 \\
\hline 22 & 15.8 & 5.8 & 21.6 & 2.7 & 0.5 & 6.7 \\
\hline 23 & 31.8 & 20.5 & 52.3 & 1.6 & 0.5 & 7.3 \\
\hline 24 & 8.6 & 10.5 & 19.1 & 0.8 & 0.6 & 5.7 \\
\hline 25 & 35.0 & 23.9 & 58.9 & 1.5 & 0.5 & 6.8 \\
\hline 26 & 2.2 & 1.6 & 3.8 & 1.4 & 0.7 & 11.3 \\
\hline 27 & 4.4 & 4.5 & 8.9 & 1.0 & 0.2 & 6.5 \\
\hline 28 & 1.6 & 0.7 & 2.3 & 2.3 & 0.2 & 6.0 \\
\hline 29 & 1.5 & 1.1 & 2.6 & 1.4 & 0.2 & 6.9 \\
\hline 30 & 2.8 & 1.5 & 4.3 & 1.9 & 0.3 & 7.8 \\
\hline 31 & 1.5 & 1.4 & 2.9 & 1.1 & 0.3 & 6.8 \\
\hline 32 & 3.3 & 1.5 & 4.8 & 2.2 & 0.3 & 5.6 \\
\hline 33 & 7.0 & 4.4 & 11.4 & 1.6 & 0.4 & 6.4 \\
\hline 34 & 12.0 & 6.4 & 18.4 & 1.9 & 0.4 & 6.1 \\
\hline 35 & 86.0 & 58.5 & 144.5 & 1.5 & 6.8 & 58.0 \\
\hline 36 & 70.0 & 44.2 & 114.2 & 1.6 & 5.6 & 45.0 \\
\hline 37 & 70.0 & 74.0 & 144.0 & 0.9 & 8.5 & 70.0 \\
\hline 38 & 85.0 & 39.1 & 124.1 & 2.2 & 6.1 & 56.0 \\
\hline 39 & 74.0 & 36.6 & 110.6 & 2.0 & 7.2 & 62.0 \\
\hline 40 & 79.0 & 33.9 & 112.9 & 2.3 & 8.1 & 60.0 \\
\hline
\end{tabular}

olive oil are still an unexplored world. It is known that their content is affected by three basic factors: (i) ripening stage of olives; (ii) postharvest storage conditions; (iii) oil filtration [13]. The introduction of Directive EU 61/2011 and successive modifications stirred up a hornets' nest for a series of motivations. Olive oil traders have strongly disapproved the limits set by the Directive EU 61/2011 for alkyl esters content, which corresponds to $\leq 75 \mathrm{mg} / \mathrm{kg}$. This value was considered too strict to be complied with, risking to be noxious to both prestige and market of olive oil. Despite the general complaint, the present Directive number 1830/2015 set specific ranges for ethyl esters (FAEEs), specifying that their content must be $\leq 40 \mathrm{mg} / \mathrm{kg}$, for EVOOs produced in the season 2013-14; $\leq 35 \mathrm{mg} / \mathrm{kg}$, for EVOOs produced in the season 2014-16; $\leq 30 \mathrm{mg} / \mathrm{kg}$, for EVOOs produced in following seasons. Although not considered in the present EU Regulation, fatty acid methyl esters were quantified and reported as well in this study. In fact, olives overripening, with 


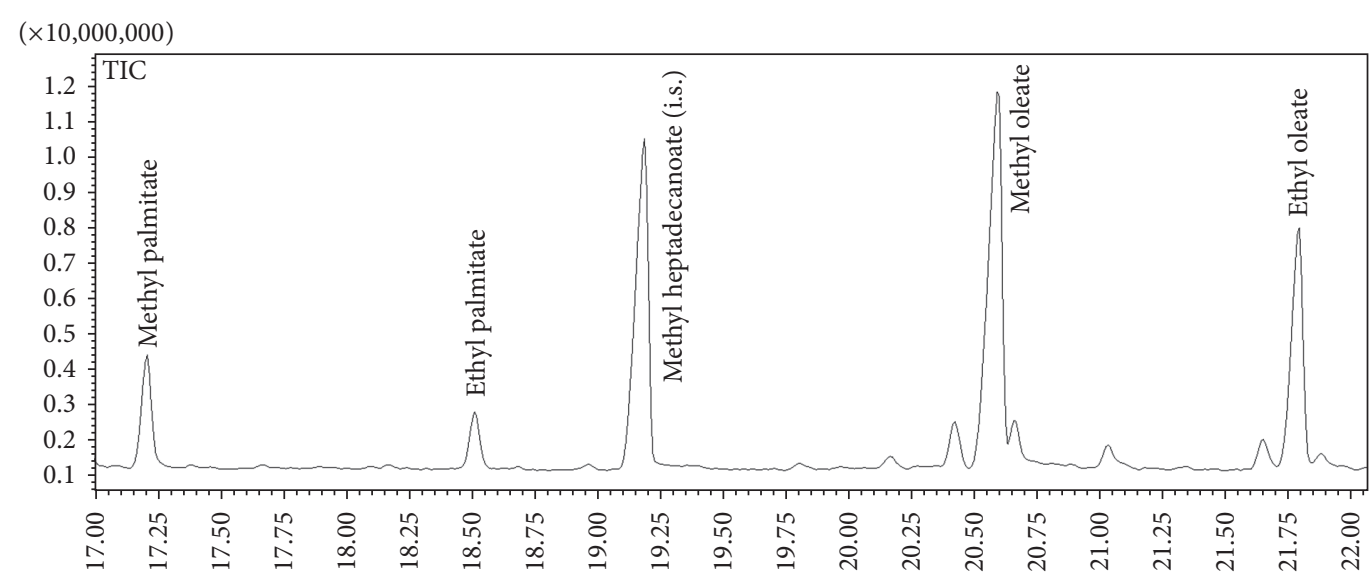

FIGURE 1: GC-MS profile of alkyl esters fraction from sample number 39 (Biancolilla variety, aged oil).

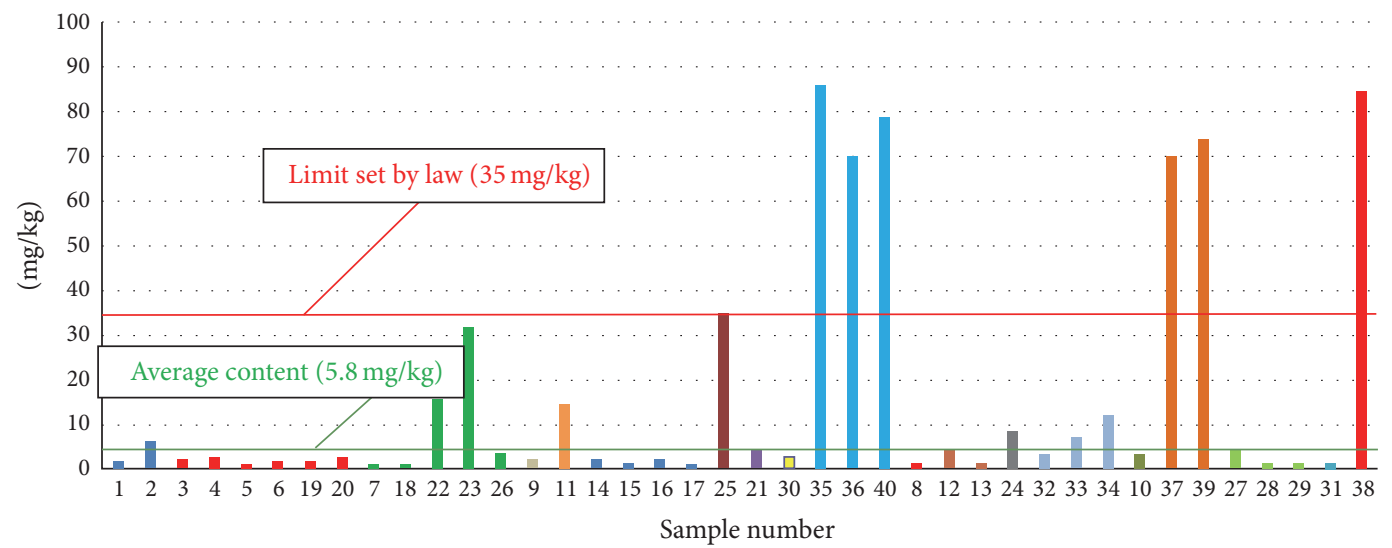

FIGURE 2: Distribution of fatty acid ethyl esters in samples grouped by zone of production. Samples sharing the same origin are grouped by colour. Values of aged EVOOs are not accounted in the average content.

consequent cell damage, is directly linked to the formation of methanol by breakdown of pectins in olive cells.

Before the introduction of EU Regulations, a Spanish research group proposed the alkyl esters as a useful tool for detection of deodorized oils in EVOOs [14]. In this previous study, among others, 15 samples of Spanish PDO oils were analyzed for the determination of their FAAEs content. Values ranged from 0.0 to $38.9 \mathrm{mg} / \mathrm{kg}$, with an average amount of $17.06 \mathrm{mg} / \mathrm{kg}$ (versus $10.3 \mathrm{mg} / \mathrm{kg}$ of this present report). More recently, the same authors coupled the chemical determination of alkyl esters to sensorial analysis, concluding that good reproducibility could be observed for the two types of evaluation [15].

An important research project, focused on monitoring the alkyl esters content in Italian EVOOs, has been carried out in the years 2012-2014 [13]. Four hundreds EVOOs were investigated, leading to the following conclusions. Principal component analysis (PCA) showed that oils distribution depended only on "quality," while it was independent on provenance or cultivar. This result was in agreement with the present study. Some samples reported a FAEEs content out of the range set by Regulation. The content of ethyl esters demonstrated to be a valid quality indicator in particular of fermentation occurred in processed olives. A limit for FAEEs of $30 \mathrm{mg} / \mathrm{kg}$ versus the present $35 \mathrm{mg} / \mathrm{kg}$ was proposed for EVOOs produced in the season 2014/15 (Directive EU number 1348/2013).

\section{Conclusions}

Although there are no official estimates, it can be assumed that the devastating death of olive crops caused by Xylella pest in some regions of South Italy has even incremented the perpetration of frauds. This is an additional reason to widen the scientific work on the assessment of olive oil authenticity and quality, necessary for both olive oil producers and consumers.

In this study, one of the new parameters introduced by EU for quality check of olive oils, namely, the alkyl esters content, has been investigated. In particular, 40 samples from Sicilian orchards have been subjected to the analytical protocol dictated by the European Union for the determination of alkyl esters, as an indicator of quality of olive oil. All the samples analyzed resulted to be in compliance with well below the limit set by EU Directive, with the exception of some very aged EVOOs. It was demonstrated that the alkyl 
esters content increases in correspondence of deterioration processes.

\section{Additional Points}

Practical Applications. This study gives insights into a topic quite hot in the field of olive oil production: the introduction of new EU Directives aimed at the unveiling of frauds. These Regulations are of very recent introduction, and both scientific community and olive oil traders unanimously agree that the limits set are quite disputable and need to be reviewed. Above all, reports on this issue are so far quite scarce, making this research study a valid source of information. The extra virgin olive oils analyzed were from the country and the region with the highest number of PDO (protected designation of origin) olive oils.

\section{Competing Interests}

The authors declare that they have no competing interests.

\section{References}

[1] European Commission Regulation, "EU no. 1348/2013 of 16 December 2013 amending Regulation no. 2598/91 on the characteristics of olive oil and olive-residue oil and on the relevant methods of analysis," Official Journal of the European Communities, vol. L338, pp. 31-67, 2013.

[2] International Olive Council, 2016, http://www.internationaloliveoil.org/.

[3] F. A. Madau, "Trends in the world olive oil sector market," MPRA paper no. 26803, 2009.

[4] European Commission Regulation, "Commission regulation (EEC) no. 2568/91 of July 1991 on the characteristics of olive oil and olive-residue oil and on the relevant methods of analysis," Official Journal of the European Communities, vol. L248, pp. 183, 1991.

[5] European Commission Regulation, "Commission regulation (EEC) no. 1996/92 of 15 July 1992 amending Regulation (EEC) no. $2568 / 91$ on the characteristics of olive oil and olive-residue oil and on the relevant methods of analysis," Official Journal of the European Communities, vol. L199, pp. 18-19, 1992.

[6] European Commission Regulation, "Commission regulation (EEC) no. 640/2008 of July 2008 on the characteristics of olive oil and olive-residue oil and on the relevant methods of analysis," Official Journal of European Communities, vol. 178, pp. $11-16,2008$.

[7] European Commission Regulation, "EU no. 61/2011 of 24 January 2011 amending Regulation no. 2598/91 on the characteristics of olive oil and olive-residue oil and on the relevant methods of analysis," Official Journal of the European Communities, vol. L23, pp. 1-13, 2011.

[8] G. Di Bella, R. Maisano, L. La Pera, V. Lo Turco, F. Salvo, and G. Dugo, "Statistical characterization of Sicilian olive oils from the Peloritana and Maghrebian zones according to the fatty acid profile," Journal of Agricultural and Food Chemistry, vol. 55, no. 16, pp. 6568-6574, 2007.

[9] L. Mannina, G. Dugo, F. Salvo et al., "Study of the cultivarcomposition relationship in sicilian olive oils by GC, NMR, and statistical methods," Journal of Agricultural and Food Chemistry, vol. 51, no. 1, pp. 120-127, 2003.
[10] G. Dugo, L. La Pera, D. Giuffrida, F. Salvo, and V. Lo Turco, "Influence of the olive variety and the zone of provenience on selenium content determined by cathodic stripping potentiometry (CSP) in virgin olive oils," Food Chemistry, vol. 88, no. 1, pp. 135-140, 2004.

[11] M. L. Clodoveo, S. Camposeo, R. Amirante, G. Dugo, N. Cicero, and D. Boskou, "Research and innovative approaches to obtain virgin olive oils with a higher level of bioactive constituents," in Olive and Olive Oil Bioactive Constituents, D. Boskou, Ed., pp. 179-215, AOCS Press, Urbana, Ill, USA, 2015.

[12] European Commission Regulation, "EU no. 1830/2015 of 8 July 2015 amending regulation no. 2598/91 on the characteristics of olive oil and olive-residue oil and on the relevant methods of analysis," Official Journal of the European Communities L, vol. 266, pp. 9-13, 2015.

[13] L. Di Giacinto, G. Di Loreto, G. Di Serio et al., Monitoraggio degli Alchil Esteri (AE) Nellolio Extra Vergine di OlivaMONITORALCHIL_Risultati dell'attività Sperimentale, D\&D Arti Grafiche, Torre de Passeri, Italy, 2014.

[14] M. D. C. Pérez-Camino, A. Cert, A. Romero-Segura, R. CertTrujillo, and W. Moreda, "Alkyl esters of fatty acids a useful tool to detect soft deodorized olive oils," Journal of Agricultural and Food Chemistry, vol. 56, no. 15, pp. 6740-6744, 2008.

[15] R. B. Gómez-Coca, W. Moreda, and M. C. Pérez-Camino, "Fatty acid alkyl esters presence in olive oil vs. organoleptic assessment," Food Chemistry, vol. 135, no. 3, pp. 1205-1209, 2012. 

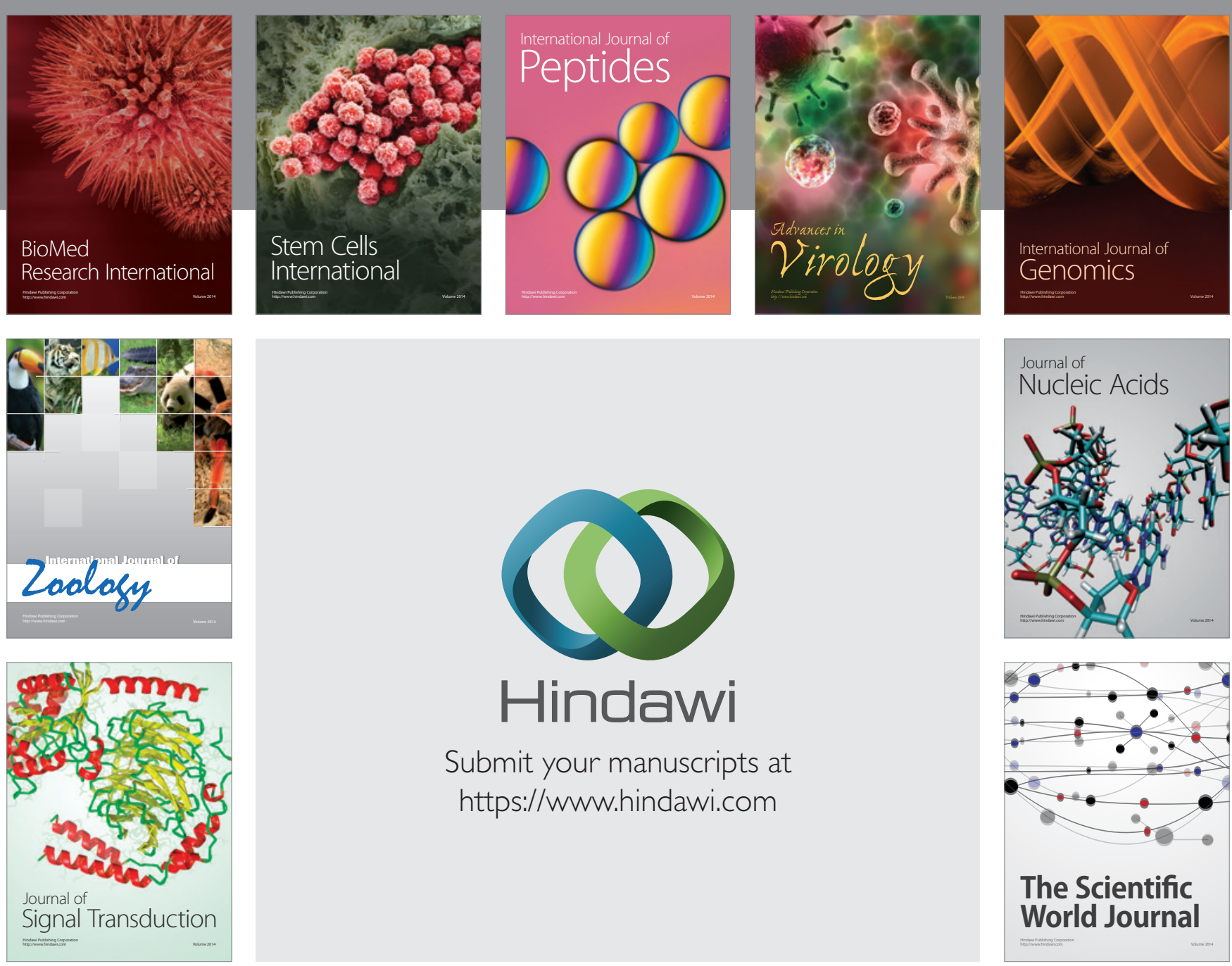

Submit your manuscripts at

https://www.hindawi.com
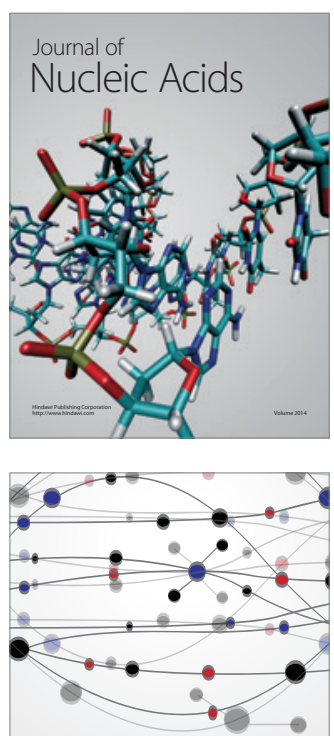

The Scientific World Journal
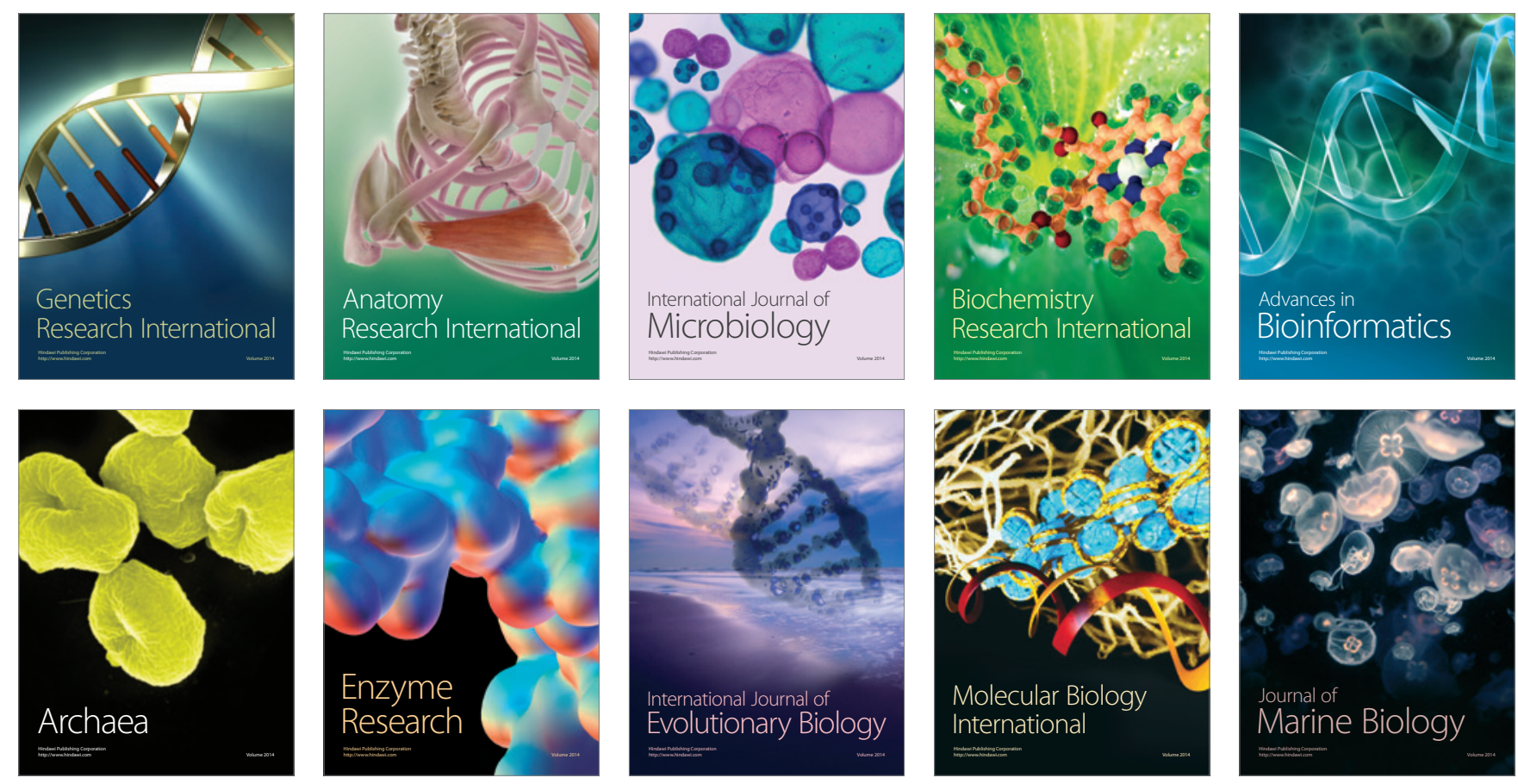